\title{
A Comparison between Children with ADHD and Children with Epilepsy in Self-Esteem and Parental Stress Level
}

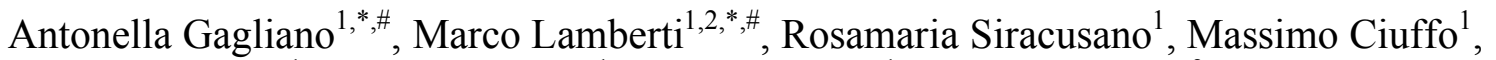 \\ Maria Boncoddo ${ }^{1}$, Roberta Maggio ${ }^{1}$, Simona Rosina ${ }^{1}$, Clemente Cedro $^{3}$ and Eva Germanò ${ }^{1}$
}

\author{
${ }^{I}$ Division of Child Neurology and Psychiatry, University of Messina, Italy; ${ }^{2}$ Department of Clinical and Experimental \\ Medicine, University of Messina, Italy; ${ }^{3}$ Division of Psychiatry, University of Messina, Italy
}

\begin{abstract}
Attention-deficit/hyperactivity disorder (ADHD) is frequently associated with negative psychological outcomes. This study explores the relationship between self-esteem, ADHD symptoms and parental stress. It compares children with ADHD, children with epilepsy (E) and typical developmental controls (TD). Participants included 65 children (aged 9-12 yrs) and their parents. The assessment was conducted by Multidimensional Self-Concept Scale (MSCS), Parent Stress Index (PSI) and Conners' Parent Rating Scales-Revised. Significant differences were found in Social, Competence and Academic areas of self-esteem between children with ADHD, with E and TD. Moreover, parents of children with ADHD showed a higher overall stress than both other groups. In conclusion, it seems important to evaluate the psychological aspects of ADHD condition, both in children and in parents, in order to suggest an individual multimodal treatment.
\end{abstract}

Keywords: Attention-deficit/hyperactivity disorder, children, epilepsy, parental stress, self-esteem.

\section{INTRODUCTION}

Several syndromes and developmental disorders are commonly associated with low levels of self-esteem. Conversely, a low self-esteem may be a signal of distress associated with serious impairments in psychological development. Attention-deficit/hyperactivity disorder (ADHD), a common child and adolescent disorder, is frequently associated with low self-esteem and low self-perception, negative outcomes and emotional and behavioural problems [1, 2]. ADHD makes it difficult to achieve success and fulfillment at school [3], at home and during free time. Increasingly, the literature suggests that affected children are more likely to experience school failure, poor peer relationships, and familial conflict [4-6]. In particular, lower scores in sub-domains of selfesteem such as "skills and talents" and "psychological wellbeing" in children with high scores of ADHD symptoms have been reported [7]. On the whole, low self-esteem has been associated with feelings of inadequacy and frustration which in turn can result in the worsening of behavioural symptoms. Indeed, a poor self-concept related to academic competence can directly contribute to the development of disruptive, antisocial behaviors in early adolescence [8].

However, findings from previous studies investigating the relationship between Attention-deficit/hyperactivity disorder (ADHD) and self-esteem are inconsistent. Some studies indicate that self-esteem scores are lower in children with ADHD than typical developmental children (TD) [2, 8, 9], others report that self-esteem scores are higher in children

*Address correspondence to this author at the Division of Child Neurology and Psychiatry, University of Messina, Italy;

E-mail: mlamberti@unime.it

"Joint first authors with ADHD [10]. In particular elementary-age children with ADHD display overly positive self-perceptions, a condition described as a "positive illusory bias" (PIB) [11-13]. The PIB has been defined in the following way: "children with ADHD unexpectedly provide extremely positive reports of their own competence in comparison to other criteria reflecting actual competence" [14]. Current literature supporting the presence of the PIB in individuals with ADHD has been conducted primarily with elementary-age students. However, academic and social problems associated with ADHD may become more prominent during adolescence due to the increasing academic demands and the increased emphasis on peer acceptance [15]. Interestingly, self-concept seems to decrease with age in children with ADHD and those with internalizing problems are at greater risk for poor self-esteem [16]. ADHD adolescent's sense of self can also be affected by both the core symptoms and environmental factors, such as parental difficulty in managing their children [17]. Some authors, using twin methodology [18] have argued for the existence of a long-term relationship between ADHD symptoms reported by parents, measured at 8 years of age, and a self-report of low self-esteem measured at 13 years. They suggested that children with ADHD may experience heightened risk of developing clinically low self-esteem in early adolescence.

The current study examines the relationship between ADHD and self-esteem, and observes how self-esteem impacts on the relation between parental stress and ADHD symptoms. We hypothesized that children with ADHD have a self-esteem even lower than children with a chronic and severe condition as epilepsy. In fact, children with epilepsy do not always show lower self-esteem than their peers [1921] and some studies indicate that children with physical 
impairments are not always impaired as regards their selfesteem [22]. However, epilepsy is commonly considered a very debilitating disease that could have a strong impact on self-esteem because of the clear perception of the illness, the need for long-term drug therapy, the social stigma attached to the illness and other resulting problems [23]. In a certain sense the characteristics of the epileptic condition could be considered very close to of ADHD characteristics. Moreover, parents of patients with epilepsy are directly involved in the management of children's condition just as the parents of children with ADHD. Taking into consideration these similarities, we decided to compare children with ADHD to children with epilepsy.

An additional goal of the current study was to determine the extent to which perceived parental stress is related to the management of children with ADHD symptoms. It is well known that parents of children with ADHD experience elevated levels of caregiver stress. Many studies have reported very high parent stress levels related to the severity of children's ADHD symptoms, aggression, emotional liability, and executive functioning difficulties [24]. Recent research has shown that the perceived impairments in children's selfregulation across emotional, cognitive, and behavioural domains are what parents report as stressful, not simply the severity of ADHD symptoms [25]. As a matter of fact, the link between child behaviours and maternal distress seems strengthened by maternal risk and attenuated by child behavioural self-esteem [26]. Thus, we planned to exam the correlation between child self-esteem and parental stress.

\section{METHODS}

\section{Sample}

Subjects attending our programs in the Unit of Child Neurology and Psychiatry of the University Clinic were considered for the study. The study was approved by the local Ethics Committee.

Participants included 65 children and their parents: 22 children with a diagnosis of ADHD (according to DSM-IVTR criteria; 17 combined subtype and 5 inattentive subtype) aged $9-12$ years $(M=10,14, S D=.990), 20$ children with Epilepsy (Idiopathic epilepsy with partial or secondarily generalized seizures) aged 9-12 years $(M=10,85, S D=$ .813 ), and 23 typically developing children (TD) recruited in two different schools in Messina and examined within their school environment. The groups were comparable for gen- der, age of patient and parents, level of education, number of siblings and socio-economic background. Demographic features are reported in Table 1.

We excluded subjects with low IQ (total IQ below 85 at WISC-III scale), specific learning disorders (such as dyslexia), major neurological signs and sensory deficits.

At the moment of evaluation, 10/22 patients with ADHD were on pharmacological treatment with stimulants, and $12 / 20$ patients with epilepsy were on antiepileptic drugs ( 5 with acid valproic, 4 with carbamazepine, 3 with levetiracetam).

\section{Measures}

Multidimensional Self Concept Scale [27] SCS, Bracken, 1993; MTA Italian version Beatrice \& Bracken,2005) was used to investigate the participants' global level of self-esteem.

MSCS is a self-report instrument, which consists of 150 items exploring six areas by six subscales: Social, Competence, Affect, Academic, Family and Phisical. MSCS subscales analyze some personal traits and social characteristics (see Table 2). The information about the person/individual in several domains of varying contexts is used to create multidimensional personal profiles [28]. Therefore, an individual value profile consists of the values in the variables constituting the profile, described by the subscales of the questionnaire. The multiple answering options are: Absolutely True, True, False, Absolutely False.

Parenting Stress Index [29] is used to measure parental stress level. This self-report instrument is aimed to explore the stress levels of parents or caregivers. It consists of 36 items that describe feelings and behaviours related to parental stress. Five answering options are proposed for each item: Absolutely Agree (AA), Agree (A), Not Sure (NS), Disagree (D), Absolutely Disagree (AD).

The instrument is based on the assumption that parental stress originates not only from characteristics of children and parents but also from socio-demographic features.

It analyzes three subscales:

- Parental Distress (PD)

- Parent-Child Dysfunctional Interaction (P-CDI)

- Difficult Child (DC)

Table 1. Demographic characteristics of children with Attention-Deficit/Hyperactivity Disorder (ADHD), epilepsy and typical developmental.

\begin{tabular}{|c|c|c|c|c|c|c|}
\hline \multirow[b]{2}{*}{ Age children } & \multicolumn{2}{|c|}{$\begin{array}{c}\text { ADHD } \\
\text { Mean SD }\end{array}$} & \multicolumn{2}{|c|}{$\begin{array}{c}\text { EPILEPSY } \\
\text { Mean SD }\end{array}$} & \multicolumn{2}{|c|}{$\begin{array}{c}\text { TD } \\
\text { Mean SD }\end{array}$} \\
\hline & 10,14 & ,990 & 10,85 & ,813 & 10,61 & 1,08 \\
\hline Siblings & 1,14 & 1,16 & 1,33 &, 594 & 1,22 & 671 \\
\hline Age mother & 40,4 & 3,95 & 41,20 & 5,1 & 42,39 & 5,0 \\
\hline
\end{tabular}

$\mathrm{p}<0,05 \mathrm{p}<0,01$ 
Table 2. MSCS subscales.

\begin{tabular}{|l|}
\hline Social subscale: social competence related to interactions with others; \\
\hline Competence subscale: success/failure in attainment of goals: \\
\hline Affect subscale: recognition if affective behaviors \\
\hline $\begin{array}{l}\text { Academic subscale: academic achievement and competence in other } \\
\text { school-related activities: }\end{array}$ \\
\hline Family subscale: competence related to interaction with family members \\
\hline Physical subscale: physical attractiveness and prowess. \\
\hline
\end{tabular}

Conners' Parent Rating Scales-Revised, [30] is commonly used to quantify ADHD symptoms. We asked the parents to complete the Conners' Parents Rating Scales Revised, Short Form (CPRS-R:S , Conners, 1989). The CPRS$\mathrm{R}: \mathrm{S}$ contains 27 items and covers a subset of the subscales and items on the long parent form.

It provides the following sub-scores:

- Oppositional : probes like children are " predisposed " to break rules,

- Cognitive Problems/Inattention: probes like subject may experience learning difficulties, of difficulty in organizing school work,

- Hyperactivity : probes like subject finds it difficult to sit in the classroom or pay attention for a long-time,

- ADHD Index: probes to identify children / adolescents "at risk" of ADHD.

\section{Statistical Analyses}

Descriptive analyses were used to analyze demographic and clinical characteristics of the whole sample. Chi-square analyses were performed on categorical variables and unpaired t-test on continuous variables. Bonferroni multiple comparison method was performed to compare the test variables between each group. Effect size was calculated for relevant differences by Hedge method. Furthermore, correlation analyses were performed between variables for each group using Pearson's correlation coefficients.

\section{RESULTS}

Significant differences were found across the explored domains between children with ADHD, and typically developing children. Table 3 and Fig. (1) show the means and SD of the differences in MSCS domains between the three groups.

There are statistically significant differences in MSCS subscales between the ADHD group and TD group in the Social area $(p, 004)$, in the Competence area $(p, 008)$ and in the Academic area $(p, 032)$. Even if the mean overall MSCS scores of children with ADHD is not greatly impaired, some subjects out of the whole group obtained very low scores, as shown in Fig. (2). Notably, patients with ADHD obtained higher scores in "Physical" subscale compared to the other two groups (see Fig. 2). Conversely, no statistical differences emerged between children with epilepsy and typically developing controls in any of the MSCS areas and between ADHD and children with epilepsy. In one out the MSCS subscales (Family) children with epilepsy showed a higher level of self-esteem than typically developing children.

Analysing the PSI scores, we observed that parents of children with ADHD had significantly higher scores than parents of typically developing children. Parent Stress Index (PSI) mean scores, analysed by Bonferroni multiple comparison for all parameters, between ADHD group, epilepsy group and TD group, were significantly different (see Table 4). ADHD group and TD group differ significantly in P-CDI (Parent-Child Dysfunctional Interaction, $p, 000)$, DC (Difficult Child, $p, 000)$ and PSI -TS (Parental stress index total score sub-scores, $p, 000)$ sub-scores.

But also the difference between Epilepsy group and ADHD group was statistically significant in P-CDI (ParentChild Dysfunctional Interaction, $p, 018$ ) and DC (Difficult Child, $p$,028) sub-scores. Therefore, parents of children with ADHD showed a higher overall stress than both the parents of TD and epilepsy groups (see Fig. 2).

Table 3. Mean scores, SD and bonferroni multiple comparison method for all parameters of Multidimensional self concept scale (MSCS): comparison between children with attention-deficit/hyperactivity disorder (ADHD), epilepsy and typical developmental. Effect size by g of hedge.

\begin{tabular}{|c|c|c|c|c|c|c|c|c|c|c|}
\hline \multirow{2}{*}{$\begin{array}{c}\text { MSCS Domains } \\
\text { Social }\end{array}$} & \multicolumn{2}{|c|}{$\begin{array}{c}\text { ADHD } \\
\text { Mean SD }\end{array}$} & \multicolumn{2}{|c|}{$\begin{array}{c}\text { EPILEPSY } \\
\text { Mean SD }\end{array}$} & \multicolumn{2}{|c|}{$\begin{array}{c}\text { TD } \\
\text { Mean SD }\end{array}$} & \multicolumn{3}{|c|}{$\begin{array}{c}\text { P value } \\
\text { A/E A/C E/C }\end{array}$} & \multirow{2}{*}{$\begin{array}{c}\text { Effect Size } \\
\boldsymbol{t}\end{array}$} \\
\hline & 91,7 & 12,0 & 100 & 13,8 & 104,1 & 11,5 & 109 &, $004 * *$ & ,847 & \\
\hline Competence & 90,2 & 14,5 & 94,1 & 13,9 & 102,9 & 12,1 & 1 &, $008 * *$ & ,115 & $>1$ \\
\hline Affect & 97,0 & 12,7 & 102,6 & 12,2 & 103,0 & 9,1 & ,356 &, 260 & 1 & \\
\hline Family & 97,1 & 9,7 & 103,2 & 9,4 & 99,0 & 10,5 & ,153 & 1 &, 527 & \\
\hline Physical & 105,1 & 12,1 & 102,1 & 14,8 & 103,6 & 10,5 & 1 & 1 & 1 & \\
\hline MSCS tot & 95,4 & 11,4 & 101,6 & 10,5 & 102,5 & 10,6 & 212 & ,094 & 1 & \\
\hline
\end{tabular}

$* \mathrm{p}<0,05 * * \mathrm{p}<0,01$ 


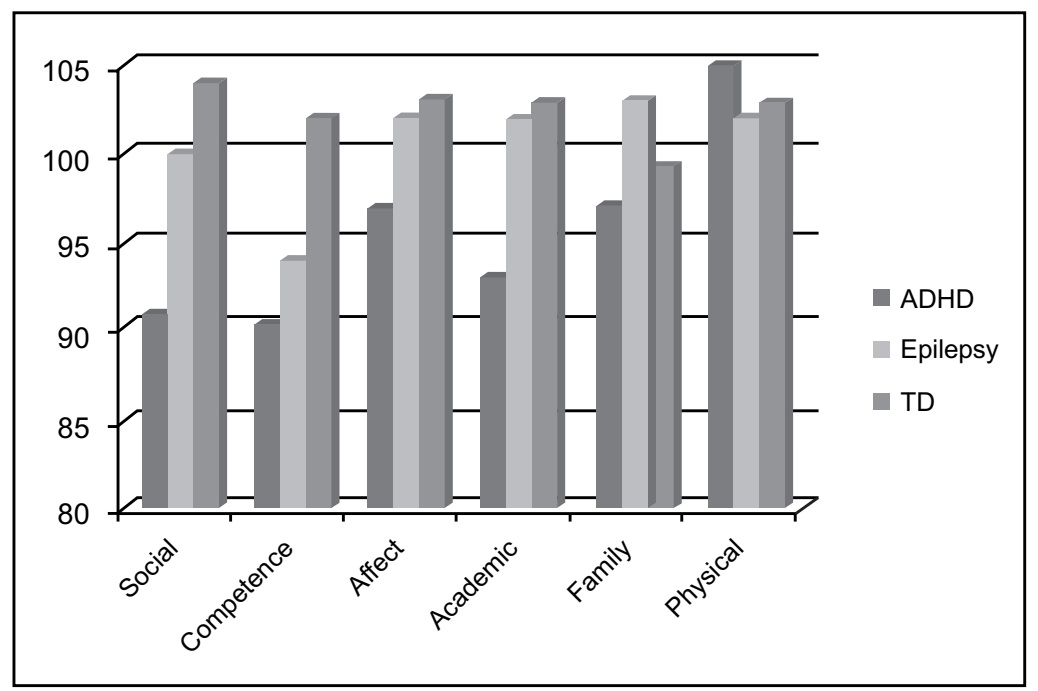

Fig. (1). Comparison between the three groups in MSCS.

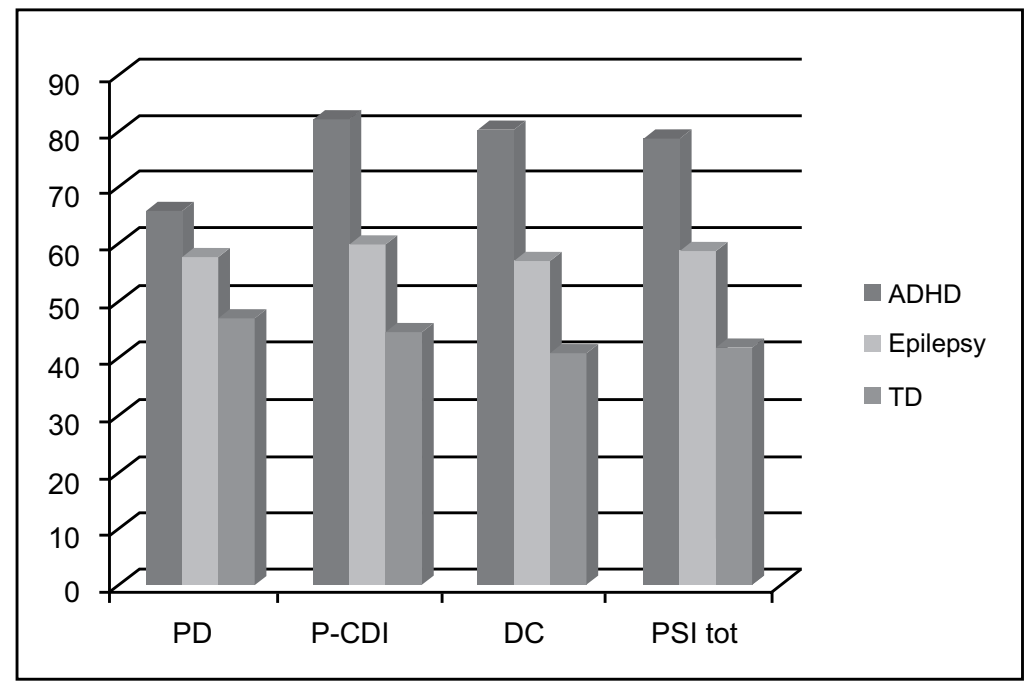

Fig. (2). Comparison between the three groups in PSI.

Table 4. Mean scores, SD and bonferroni multiple comparison method for all parameters of parent stress index (PSI): comparison between Attention-Deficit/Hyperactivity Disorder (ADHD), epilepsy and typical developmental children's parents.

\begin{tabular}{|c|c|c|c|c|c|c|c|c|c|c|}
\hline \multirow{2}{*}{ PSI Domains } & \multicolumn{2}{|c|}{$\begin{array}{c}\text { ADHD } \\
\text { Mean SD }\end{array}$} & \multicolumn{2}{c|}{$\begin{array}{c}\text { EPILEPSY } \\
\text { Mean SD }\end{array}$} & \multicolumn{2}{c|}{$\begin{array}{c}\text { TD value } \\
\text { Mean SD }\end{array}$} & \multicolumn{3}{c|}{ EfE A/C E/C } \\
\hline \hline PD & 66,8 & 30,0 & 58,5 & 27,1 & 47,1 & 26,7 & 1 &, 065 &, 574 &, 090 \\
\hline P-CDI & 82,5 & 21,4 & 60,5 & 29,4 & 43,5 & 23,9 &, $018 *$ &, $000 * *$ & $>1$ \\
\hline DC & 80,2 & 25,2 & 57,7 & 25,8 & 41,7 & 27,1 &, $028 *$ &, $000 * *$ &, 150 & $>1$ \\
\hline PSI TS & 79,4 & 27,1 & 59,5 & 25,7 & 42,4 & 26,2 &, 064 &, $000 * *$ &, 115 & $>1$ \\
\hline
\end{tabular}

$[\mathrm{PD}=$ Parent Distress; $\mathrm{P}-\mathrm{CDI}=$ Parent-Child Dysfunctional Interaction; $\mathrm{DC}=$ Difficult Child; PSI TS $=$ Parental stress index total score]. *p $<0,05 * * \mathrm{p}<0,01$

In order to examine the sources of parental stress, we analysed the statistical relationship between PSI scores and other variables. Specifically, we described the correlations between PSI scores and children's age (as continuous variables), drug treatment (as dichotomous variable describing if the child was or was not on drug treatment), the Conners' rating scale scores (as continuous variables describing symptoms) and the MSCS scores (as continuous variables describing self-esteem level). Only some demographic and behavioural variables seem related to parental stress: Table $\mathbf{5}$ shows the significant correlations. No significant correlations emerged between MSCS and PSI scores. 


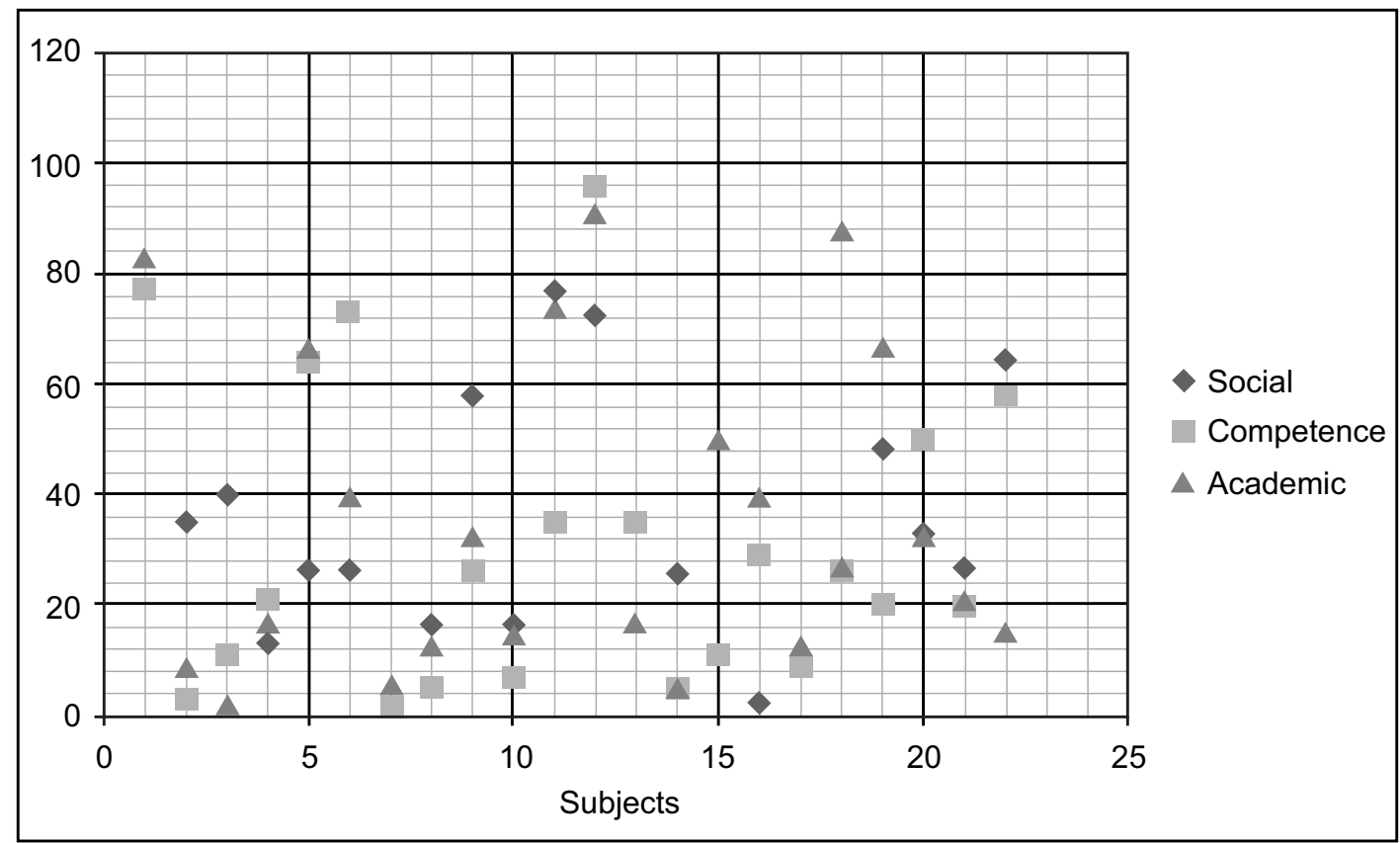

Scatter Diagram of MSCS subscales in ADHD group.

Table 5. PSI domains and several variable correlation. The table shows only the significant correlations $(p<$ 0,01).

\begin{tabular}{|c|c|c|c|}
\hline & Children Age & Drug & Conners Opp. \\
\hline \hline PSI TS & .516 & & .614 \\
\hline DC (PSI) & .727 & & .498 \\
\hline P-CDI & & .514 & .516 \\
\hline
\end{tabular}

[PSI TS $=$ Parental stress index total score; DC $=$ Difficult Child; P-CDI= Parent-Child Dysfunctional Interaction]

Conversely, it appears that higher scores in CPRS oppositional subscale are closely related to higher scores in parental stress level, as measured by "PSI total score", "Difficult Child" and "Parent-child dysfunctional interaction" scores. Furthermore, higher age of children appears related to "PSI total score" and "Difficult Child" sub-scale scores.

Instead, there were no significant correlations between MSCS scores and other CPRS behavioural sub-domains scores (inattention and hyperactive/impulsive). Finally, the parents of treated children with ADHD show higher stress levels than parents of non-treated children with ADHD, as expressed by the significant correlation between "parentchild dysfunction interaction" and the dichotomous variable describing whether the child was or was not on drug treatment.

\section{DISCUSSION}

In accordance with literature supporting the relationship between clinically-diagnosed children with ADHD and low levels of self-esteem, the first purpose of this study was to compare the levels of self-esteem in children with ADHD compared to typically developing and epileptic children. Results suggest that children with ADHD actually have a different level of self-esteem compared to children without ADHD. Self-esteem is both a cognitive and emotional concept that describes the individual's idea and values about $\mathrm{him} /$ herself. Self-esteem is also related to cognitive strategies that lead to successful problem-solving, which is a crucial issue in children with ADHD [28]. It is correct to regard selfesteem as a multidimensional concept and to describe different domains of the self-image in different contexts. Low scores in internal domains of self-esteem, such as "psychological well-being" and "skills and talents", have been previously reported in subjects with ADHD [7]. Our results are consistent with the conclusions of a recent paper [31] that describes a significant difference between boys with ADHD and typically developing children on some domains of selfesteem. By the Harter Self-Esteem Questionnaire, reduced scores were found in "Global Self-Esteem Subscale", "Social Acceptance Subscale" and "Scholastic Performance Subscale”.

Thus, on an individual level, children with problems related to ADHD seem to have very different profiles of selfesteem, in line with the idea that self-esteem is a multidimensional concept [32]. In this respect, some authors suggest that there is no clear link between ADHD and profiles of self-esteem [7]. They argue that the individual patient with ADHD could have low self-esteem in some domains of selfesteem, but on the whole self-esteem could be quite good. Also in our study, the mean overall MSCS scores of children with ADHD is not greatly impaired, but some subjects out of the whole group showed very low scores. In more details, children with ADHD exhibited lower self-esteem scores in three domains ("Social", "Competence" and "Academic") rather than a global decrease in all areas.

These findings suggest that children's concerns can be focused on developing friendships and good family interactions and school achievements as well. This can be considered a likely consequence of the social and academic failures 
that children with ADHD commonly have. It is usual for children with ADHD to be criticized and reproached due to their maladaptive behaviours. This condition can lead to develop the idea that nobody appreciates and regards them. Given that children with ADHD lack expertise in most domains, their overly positive self-views of competence promote learning or persistence on difficult tasks that might otherwise prove too discouraging [33].

The only domain in which children with ADHD exhibited a higher self-esteem level than the other two groups was the physical subscale that describes the children's perception of their body and their ability in physical activities. This is a somewhat expected finding since children with ADHD can show good self-confidence in their physical ability due to their high levels of energy and strength. The relatively good self-esteem in physical competence in children with ADHD is in some way consistent with the "positive illusory bias", that is to say that the children have a tendency to overestimate their abilities [12]. In this model it has been argued that the self-enhancement could be a way of neglecting the individual's lack of skills that he/she does not want others to know about [34]. Actually it seems likely that children with ADHD have a really strong perception of their physical power due to their dynamic behavioural pattern and to their get-up-and-go when dealing with peers or older persons.

By examining the mean MSCS score differences between children with ADHD and similar-aged epileptic children, we were able to compare the self-esteem pattern in both social and behavioural domains. As previous studies have reported [19], our results confirm that children with epilepsy do not have a significantly lower self-esteem than the control group even though they have a relatively compromised well-being and comprehensive care needs which go beyond the attempt of controlling seizures. Epilepsy can significantly affect quality of life $[21,35]$ not only because of its chronicity, the necessity for medication, and their side effects [36], but also due to the prejudices and social conventions that still surround the condition [37].

It is noteworthy that our children with ADHD seem less capable than children with epilepsy to protect themselves from the emotional negative impact of their symptoms on the self-esteem level. Conversely, children with epilepsy showed an even better self-esteem than the typically developing controls in subscale "family " of MSCS. We can assume that the parents of children with epilepsy are more prone to develop reciprocity in the parent-child relationship than the parents of children with ADHD. In fact, they have no reason to feel frustrated and angry because of their "sick" children. Instead, the functional and behavioural problems encountered by children with ADHD can be very disruptive for their families and often lead to conflictive parent-child relationships which can in turn impact children's self-esteem. In fact, when a child displays hyperactivity, inattention, and/or oppositional behaviour, even parents with a high level of care, may respond with dissatisfaction, anger and intolerance. This can lead to a high degree of frustration in children. It is therefore not surprising that the presence of ADHD in children is associated with reduced parenting self-efficacy, lower parental satisfaction and increased levels of parental stress, as indicated by several studies [24, 25]. These suggestions, taken as a whole, propose a possible protective effect on self-esteem as a result of a positive, caring and not frustrated parentchild relationship.

Our study also confirms the relationship between high levels of parental stress and ADHD [38] but does not sustain the relationship between parental stress and child selfesteem. The lack of significant correlations between MSCS and PSI scores suggests that children's self-esteem is not directly influenced by parental stress. This counterintuitive finding could be explained considering that the children's self-esteem level is mostly based on social and academic reinforcements, not only on the well-being of family environment. We could argue that the parental stress have a more modest impact on children's self-idea than the social stigma and the scholastic failure. Given that children build their self-esteem during childhood, and especially during preadolescent and adolescent stage, it is arguable that the behavioral problems could lead to poor peer relations, aggression, and learning problems which are in turn associated with academic failure and a low self-esteem. Previous reports underline how this vicious circle can even have effects on increasing of developing psychiatric disorders, such as depression [39].

Nevertheless, it seems particularly important to understand which variables are more closely related to parental stress. Interestingly in our study, parents of children with ADHD showed higher scores in PSI than parents of children with epilepsy. As correlation analysis reveals, the parental stress levels are mainly associated with oppositional symptoms rather than to inattentive and hyperactive/impulsive behaviours. Children with oppositional defiant disorder (ODD) have frequent run-ins with authority figures and oppositional behaviours, far more often than other children their age. When associated with ODD, ADHD may predispose affected children to the subsequent development of conduct disorders (CDs), delinquent behaviour, and substance misuse [5, 40, 41]. Moreover, children with ODD experience disturbances in peer and family relationships, as well as poor academic achievement [42, 43]. According to other reports, the role of ODD symptoms must be considered of greatest interest is the comorbidity with depression [44] and self-concept weakening [45].

Another interesting figure is that parents stress level increases with the children's age. This finding can be explained considering that adolescents with ADHD usually experience an increasing gap between their functional level and social and academic requirements. The difficulty to cope with this increased demand could consecutively increase parental discomfort and worsen the family relationships.

Finally, an unexpected result showed a higher parental stress level associated with drug treatment. We argue that most parents in Italy still have concerns regarding the safety of medication for treating ADHD and, more in general, a current adverse view of stimulants. Therefore, Italian parents experience stress due to the choice of medication option, even when the treatment shows efficacy in improving symptoms. This evidence is in contrast with a previous North American study [46] that revealed no differences among children on medication and children without medication on measures of family distress (eg, parenting stress, depressive symptoms among parents, marital adjustment). 


\section{CONCLUSION}

Children with ADHD may be relatively more impaired in self-esteem than other children affected with severe chronic diseases. They can have low self-esteem in some domains of self-esteem, even when the whole self-esteem is not impaired. Thus, the evaluation of self-esteem level in children and adolescents with ADHD can be helpful in guiding psycho-educational interventions that should be individualized and based on a "person-oriented approach" [7]. Timely and targeted treatment for ADHD is associated with improvement of self-esteem and consequently better outcomes [47].

At the same time, it is important to develop intervention programs designed to help parents in the identification and management of their own parenting stress. This seems mostly related to ODD symptoms that cause disturbances in peer and family relationships.

These findings emphasize the psychological aspects of ADHD condition, both in children and in parents and strongly suggest an additional focus on self-esteem problems and on parental stress in the context of a multimodal treatments for children with ADHD.

\section{LIMITATIONS AND IMPLICATIONS FOR RE- SEARCH}

The current study is limited by cross-sectional data and by a rather restricted sample. Moreover, our findings in a health care-based sample could describe the characteristics of a more severe form of ADHD with a strong prevalence of combined subtype and of male patients. This is most likely due to the reliance on parents for diagnosis, as teachers identify more problem behaviours in boys, which may contribute to higher numbers of boys treated in clinical settings [48]. Furthermore this paper includes a clinically referred males sample because they are more numerous due to their greater likelihood of disruptive behaviours. Thus, we decided to include only male subjects because females had more internalizing problems, depression, and anxiety as well as diminished self-efficacy and coping, and had less aggression and externalizing behaviors than males [49]. There are few studies addressing the issue of sex differences in self-esteem in children with ADHD. Gershon's (2002) [50] meta-analytic review of gender differences in ADHD revealed females to be rated significantly less impaired than males on hyperactivity, inattention, and impulsivity. This meta analysis found that females with ADHD manifested fewer externalizing problems, and were found to have more internalizing problems. Thus, the relationships among gender, behavior problems, and self-esteem are not well understood and require further research.

\section{CONFLICT OF INTEREST}

The authors confirm that this article content has no conflict of interest.

\section{ACKNOWLEDGEMENTS}

Declared none.

\section{REFERENCES}

[1] Hoza B. Peer functioning in children with ADHD. J Pediatr Psychol 2007; 32(6): 655-63.

[2] Shaw-Zirt B, Popali-Lehane L, Chaplin W, Bergman A. Adjustment, social skills, and self-esteem in college students with symptoms of ADHD. J Atten Disord 2005; 8(3): 109-20.

[3] Galera C, Melchior M, Chastang JF, Bouvard MP, Fombonne E. Childhood and adolescent hyperactivity-inattention symptoms and academic achievement 8 years later: the GAZEL Youth study. Psychol Med 2009; 39(11): 1895-906.

[4] Barkley RA, Fischer M, Smallish L, Fletcher K. Young adult follow-up of hyperactive children: antisocial activities and drug use. J Child Psychol Psychiatry 2004; 45(2): 195-211.

[5] Barkley RA, Fischer M, Smallish L, Fletcher K. Young adult outcome of hyperactive children: adaptive functioning in major life activities. J Am Acad Child Adolesc Psychiatry 2006; 45(2): 192202.

[6] Biederman J, Monuteaux MC, Mick E, et al. Young adult outcome of attention deficit hyperactivity disorder: a controlled 10-year follow-up study. Psychol Med 2006; 36(2): 167-79.

[7] Edbom T, Granlund M, Lichtenstein P, Larsson J-O. ADHD Symptoms Related to Profiles of Self-Esteem in a LOngitudinal Study of Twins, A person-oriented approach. J Child Adolesc Psychiatr Nurs 2008: 228-37.

[8] Pisecco S, Wristers K, Swank P, Silva PA, Baker DB. The effect of academic self-concept on ADHD and antisocial behaviors in early. J Learn Disabil 2001; 34(5): 450-61

[9] Mazzone L, Postorino V, Reale L, et al. Self-esteem evaluation in children and adolescents suffering from ADHD. Clin Pract Epidemiol Ment Health 2013; 9: 96-102.

[10] Treuting JJ, Hinshaw SP. Depression and self-esteem in boys with attention-deficit/hyperactivity disorder. J Abnorm Child Psychol 2001; 29(1): 23-39.

[11] Hoza B, Pelham WE, Jr., Dobbs J, Owens JS, Pillow DR. Do boys with attention-deficit/hyperactivity disorder have positive illusory. J Abnorm Psychol 2002;111(2): 268-78.

[12] Hoza B, Vaughn A, Waschbusch DA, Murray-Close D, McCabe G. Can children with ADHD be motivated to reduce bias in selfreports of competence? J Consult Clin Psychol 2012; 80(2): 24554.

[13] Hoza B, Murray-Close D, Arnold LE, Hinshaw SP, Hechtman L, Group MC. Time-dependent changes in positively biased selfperceptions of children with attention-deficit/hyperactivity disorder: a developmental psychopathology perspective. Dev Psychopathol 2010; 22(2): 375-90.

[14] Owens JS, Goldfine ME, Evangelista NM, Hoza B, Kaiser NM. A critical review of self-perceptions and the positive illusory bias in children with ADHD. Clin Child Fam Psychol Rev 2007; 10(4): 335-51.

[15] Wolraich ML, Wibbelsman CJ, Brown TE, et al. Attentiondeficit/hyperactivity disorder among adolescents: a review of the diagnosis, treatment, and clinical implications. Pediatrics 2005;115(6): 1734-46

[16] Houck G, Kendall J, Miller A, Morrell P, Wiebe G. Self-concept in children and adolescents with attention deficit hyperactivity. J Pediatr Nurs 2011; 26(3): 239-47.

[17] Krueger M, Kendall J. Descriptions of Self: An Exploraty Study of Adolescents with ADHD. JCAI 2001.

[18] Edbom T, Lichtenstein P, Granlund M, Larsson JO. Long-term relationships between symptoms of Attention Deficit Hyperactivity. Acta Paediatr 2006; 95(6): 650-7.

[19] Siqueira NF, Guerreiro MM, de Souza EA. Self-esteem, social support perception and seizure controllability perception in. Arq Neuropsiquiatr 2011; 69(5): 770-4.

[20] Ferro MA, Ferro AL, Boyle MH. A systematic review of selfconcept in adolescents with epilepsy. J Pediatr Psychol 2012; 37(9): 945-58.

[21] Jonsson P, Jonsson B, Eeg-Olofsson O. Psychological and social outcome of epilepsy in well-functioning children and adolescents. A 10-year follow-up study. Eur J Paediatr Neurol 2014; 18(3): 38190 .

[22] Grue L, Heiberg A. Do disabled adolescents view themsleves differently from other young people? Scand J Disabil Res 2000; 3957. 
[23] Guo W, Wu J, Wang W, et al. The stigma of people with epilepsy is demonstrated at the internalized. Epilepsy Behav 2012; 25(2): $282-8$.

[24] Pimentel MJ, Vieira-Santos S, Santos V, Vale MC. Mothers of children with attention deficit/hyperactivity disorder: relationship. Atten Defic Hyperact Disord 2011; 3(1): 61-8.

[25] Graziano PA, McNamara JP, Geffken GR, Reid A. Severity of children's ADHD symptoms and parenting stress: a multiple mediation. J Abnorm Child Psychol 2011; 39(7): 1073-83.

[26] Whalen CK, Odgers CL, Reed PL, Henker B. Dissecting daily distress in mothers of children with ADHD: an electronic diary. J Fam Psychol 2011; 25(3): 402-11.

[27] Bracken B. Test di Valutazione dell'Autostima. Trento: Edizioni Erickson 1993.

[28] Bergman LR, Magnusson D, El-Khouri B. Studying individual development in an interindividual context: A person oriented approach. Mahwah, NJ: Erlbaum Associates 2003.

[29] Abidin R. Parent Stress Index. $3^{\text {rd }}$ ed. Odessa, FL: Psychological Assessment Resources 1995.

[30] Conners CK. Conners' Rating Scales - Revised Techinical Manual. New York: Multi-Health Systems 1997.

[31] Błachno M, Kołakowski A, Wójtowicz S, et al. [Self-esteem of boys with attention deficit hyperactivity disorder - pilot study]. Psychiatr Pol 2013; 47(2): 281-91.

[32] Harter S. Cause and consequences of low self-esteem. In: Baumeister R. Ed. Children and adolescents self-esteem: The puzzle of low selfregard. New York: Plenum 1993; pp. 87-116.

[33] Bjorklund DF. The role of immaturity in human development. Psychol Bull 1997; 122(2): 153-69.

[34] Asendorpf JB, Ostendorf F. Is self-enhancement healthy? Conceptual, psychometric, and empirical analysis. J Pers Soc Psychol 1998; 74(4): 955-66.

[35] Taylor J, Jacoby A, Baker GA, Marson AG. Self-reported and parent-reported quality of life of children and adolescents. Epilepsia 2011; 52(8): 1489-98.

[36] Modi AC, Ingerski LM, Rausch JR, Glauser TA. Treatment factors affecting longitudinal quality of life in new onset pediatric. J Pediatr Psychol 2011; 36(4): 466-75.

[37] Nurmi J-E, Salmela-Aro K, Haavisto T. The strategy and attribution questionnaire: Psychometric properties. Eur J Psychol Assess 1994: p. 108-21.
[38] Deault LC. A systematic review of parenting in relation to the development of comorbidities. Child Psychiatry Hum Dev 2010; 41(2): 168-92.

[39] LeBlanc N, Morin D. Depressive Symptoms and Associated Factors in Children with Attention Deficit Hyperactivity Disorder. J Child Adolesc Psychiatr Nurs 2004; 49-55.

[40] Glass K, Flory K, Martin A, Hankin BL. ADHD and comorbid conduct problems among adolescents: associations with. Atten Defic Hyperact Disord 2011; 3(1): 29-39.

[41] van Lier PA, van der Ende J, Koot HM, Verhulst FC. Which better predicts conduct problems? The relationship of trajectories of. J Child Psychol Psychiatry 2007; 48(6): 601-8.

[42] Rey J, Walter G, Soutullo C. Oppositional defiant disorder and conduct disorder. Martin A, Volkmar FR, Ed. Lewis's child and adolescent psychiatry. Philadelphia: Lippincott Williams \& Wilkins 2007; pp. 454-66.

[43] van der Oord S, Prins PJ, Oosterlaan J, Emmelkamp PM. The association between parenting stress, depressed mood and informant agreement. Behav Res Ther 2006; 44(11): 1585-95.

[44] Boylan K, Vaillancourt T, Boyle M, Szatmari P. Comorbidity of internalizing disorders in children with oppositional defiant disorder. Eur Child Adolesc Psychiatry 2007; 16(8): 484-94.

[45] Chen L, Luo X, Wei Z, et al. Correlation study on behavioral problems and self-concept of children with. Zhong Nan Da Xue Xue Bao Yi Xue Ban 2011; 36(3): 217-22.

[46] Wells KC, Epstein JN, Hinshaw SP, et al. Parenting and family stress treatment outcomes in attention deficit hyperactivity. J Abnorm Child Psychol 2000; 28(6): 543-53.

[47] Harpin V, Mazzone L, Raynaud JP, Kahle J, Hodgkins P. LongTerm Outcomes of ADHD: A Systematic Review of Self-Esteem and Social Function. J Atten Disord 2013.

[48] Derks EM, Hudziak JJ, Boomsma DI. Why more boys than girls with ADHD receive treatment: a study of Dutch twins. Twin Res Hum Genet 2007; 10(5): 765-70.

[49] Rucklidge JJ. Gender differences in ADHD: implications for psychosocial treatments. Expert Rev Neurother 2008; 8(4): 643-55.

[50] Gershon J. A meta-analytic review of gender differences in ADHD. J Atten Disord 2002; 5(3): 143-54.

Received: June 30, 2014
(C) Gagliano et al.; Licensee Bentham Open.

Revised: August 08, 2014

Accepted: November 09, 2014

This is an open access article licensed under the terms of the Creative Commons Attribution Non-Commercial License (http://creativecommons.org/licenses/by-nc/3.0/) which permits unrestricted, non-commercial use, distribution and reproduction in any medium, provided the work is properly cited. 